\title{
EFFICACY OF RHIZOSPHERIC ORGANISM Rhizobium leguminosarum AGAINST Meloidogyne incognita IN SOYBEAN
}

\author{
Abdul Qudeer Ahmed, Nazir Javed*, Sajid Aleem Khan, Huma Abbas and Muhammad Kamran \\ Department of Plant Pathology, University of Agriculture, Faisalabad, Pakistan \\ "Corresponding author's e -mail: nazirpp2003@gmail.com
}

\begin{abstract}
Present investigation was carried out to assess the biocontrol potential of Rhizobium leguminosarum against root-knot nematode, Meloidogyne incognita on soybean. Effect of Rhizobium strains LSI-21 and CRI-29 was assessed individually and concomitantly on reproduction of $M$. incognita. In vitro studies were conducted to check the effect of Rhizobium strains on egg hatching and juvenile mortality of M. incognita. Concomitant application of Rhizobium strains was more effective in reducing egg hatching and causing juvenile mortality as compared to individual treatment. In green house, Rhizobium strains were used as soil drench and seed dressing for the management of root knot nematode on soybean. It caused considerable reduction in reproduction of root knot nematode as well as improved plant growth parameters of soybean. Seed dressing showed most significant results than soil drenching. It is interesting to note that Rhizobia not only controlled reproduction of M. incognita but also an increase in plant height, fresh and dry root shoot weight was observed. It would seem that Rhizobium being a good rhizosphere organism for field and vegetable crops presumably prevent the contact of pathogenic organisms on roots.

Keywords: Rhizobium, root-knot nematode, concomitant, soybean.
\end{abstract}

\section{INTRODUCTION}

Soybean (Glycine max L. Merrill) is native to Eastern Asia and among the one of the oldest crops grown by human. It is being grown successfully in tropical, subtropical and temperate climates. Moreover, soybean is one of the most promising crops for producing bio-energy (bio-diesel). Soybean is affected by various soil borne pathogens and among these pathogens nematodes play an important role in reducing the yield of this crop. The affected plants show the symptoms of root galling, yellowing of leaves and retarded growth. The pathogen also causes severe damage to all crops i.e. oil seed and vegetable crops. Several plant parasitic nematodes are capable of causing significant economic losses in soybean. Of the greater than 50 species of nematodes reported from soybean, the soybean cyst and root knot nematodes have received the greatest emphasis. One estimate attributed a $\$ 38.76$ million loss from reduced soybean yields caused by Meloidogyne spp. (Wrather and Koenning, 2006). Many soil microbes contain multiple beneficial traits of nutrient mobilization, production of plant growth promoting substances (PGPS) and biocontrol ability. Such organisms have a greater role in sustaining agricultural production. Plant nitrogen fixing rhizobacteria, a group of root associated bacteria, intimately interact with the plant roots and consequently influence plant health and soil fertility. They offer an excellent combination of traits useful in disease control and plant growth promotion. Amongst these bacteria, Rhizobium spp., have emerged as the largest and potentially the most promising group. Rhizobia can produce highly potent broad spectrum antimicrobial molecules against various phytopathogens, thus acting as effective biocontrol agents. In fact Rhizobium spp. can produce phytohormones, siderophores, HCN, production of secondary metabolites such as auxins, IAA, cytokinins, riboflavin and vitamins (Dakora, 2003). Rhizobia can also stimulate plant growth indirectly by suppressing or eliminating deleterious microbes by modulating competitiveness i.e. by producing siderophores (Loper and Buyer, 1991) antibiosis vs. plant pathogens (Antoun and Prevost, 2000) fungal growth inhibition (Nautiyal, 2000) by producing Hydrogen Cyanide $(\mathrm{HCN})$. Keeping in view the importance of Rhizobium spp. present study was planned to assess their biocontrol potential against root-knot nematode, $M$. incognita.

\section{MATERIALS AND METHODS}

Pure culture of $M$. incognita was prepared by single mass inoculation in eggplant seedling. The seeds of soybean were obtained from Ayub Agriculture Research Institute, Faisalabad, Pakistan. Two different Rhizobial strains were obtained from Soil Microbiology lab of Institute of Soil and Environmental Sciences University of Agriculture Faisalabad, Pakistan. Yeast Extract Mannitol Broth (YEM) growth medium for Rhizobia was prepared according to Somasegaran and Hoben (1994). Fifty $\mathrm{ml}$ of the YEM broth culture was centrifuged twice at $3000 \mathrm{rpm}$ for 20 minutes, pellets were discarded, and the filtrate obtained was used for 
bioassay against the root knot nematode. All the strains; SI21 and CRI-29 were evaluated for their biocontrol efficacy against $M$. incognita egg hatch in vitro. After extraction of eggs of root knot nematode from roots, number of eggs in $1 \mathrm{ml}$ of suspension was determined in counting chamber. Three dilutions of culture filtrates $\mathrm{S}, \mathrm{S} / 2, \mathrm{~S} / 4$ were prepared by adding distilled water. Fifty eggs in $0.5 \mathrm{ml}$ water were addaed in each block. One ml culture filtrate of each Rhizobial strain was transferred in glass cavity blocks. Then these cavity blocks were kept in incubator. Each treatment was replicated three times. Two control treatment were used; one absolute control (no pathogen and no biocontrol agent) and another control with only pathogen (ordinary control). Hundred freshly hatched juveniles suspension and $1 \mathrm{ml}$ culture filtrate of each bacterial strain was transferred separately in glass cavity blocks and kept at $25^{\circ} \mathrm{C}$ with three replications of each treatment. Mortality of juveniles was recorded after 24, 48 and 72 hours of incubation. The revival test was also conducted by transferring the immobilized nematodes into fresh water to confirm mortality in both the sets of plates.

Seeds after surface sterilization were coated with cell suspension of different Rhizobium strains were sown in plastic pots using clay and peat in equal proportion as a sticky material. Seeds were sown in plastic pots, seeds treated with distilled water without any bacterial culture served as control. One week after seedling emergence, roots of each plant were stick in with 1000 eggs $/ \mathrm{J}_{2}$ of $M$. incognita. Suspension of actively growing culture of Rhizobium strains was drenched in plastic pots having sterilized soil. Pots containing distilled water were served as control. Five replications of all treatments were made. After one week of transplantation 1000 $\mathbf{J}_{2}$ were inoculated into each pot. Observations on plant height $(\mathrm{cm})$, root, shoot and fresh along with dry weight $(\mathrm{g})$ were recorded. Dry root weight was calculated after sun drying. Harvesting was done after sixty days. The root system was rated for galling on a 0 to 10 scale (Bridge and Page, 1980). The roots were stained with Phloxine B (Southey, 1986) for counting the egg masses. Field experiments were repeated to confirm the results. Data were analyzed by analysis of variance (ANOVA) and the significance of differences within treatments were separated by using Duncan multiple range test at probability levels $P=0.05$ by using Mstat version 1.3.

\section{RESULTS}

The efficacy of the culture filtrates of the Rhizobium strains for their ability to immobilize or kill root knot nematode, $M$. incognita was studied under in vitro. Mortality percentage was in different strains. There was increase in the \% mortality of juveniles due to continuation of exposure up to 72 hours with culture filtrates of most strains. Mortality of $M$. incognita was significantly affected by different concentrations and

Table 1. Effect of Rhizobium strains on the mortality and egg hatching of M. incognita.

\begin{tabular}{lccccccc}
\hline Treatments & Dilutions & \multicolumn{3}{c}{ \% Juvenile's mortality } & \multicolumn{2}{c}{ \% Egg hatching } \\
\cline { 2 - 7 } & & 24 Hours & 48 Hours & 72 Hours & 1 Day & 3Day & 5 Day \\
\hline LSI-21 & $\mathrm{S}$ & $55 \mathrm{a}$ & $59 \mathrm{a}$ & $65 \mathrm{a}$ & $12 \mathrm{c}$ & $46 \mathrm{c}$ & $62 \mathrm{c}$ \\
CRI-29 & $\mathrm{S}$ & $70 \mathrm{a}$ & $74 \mathrm{a}$ & $79 \mathrm{a}$ & $10 \mathrm{~d}$ & $38 \mathrm{c}$ & $50 \mathrm{~d}$ \\
CRI-29 +LSI-21 & $\mathrm{S}$ & $82 \mathrm{a}$ & $85 \mathrm{a}$ & $90 \mathrm{a}$ & $6 \mathrm{c}$ & $20 \mathrm{a}$ & $32 \mathrm{a}$ \\
LSI-21 & $\mathrm{S} / 2$ & $51 \mathrm{~b}$ & $55 \mathrm{~b}$ & $60 \mathrm{~b}$ & $24 \mathrm{bc}$ & $56 \mathrm{~b}$ & $72 \mathrm{bc}$ \\
CRI-29 & $\mathrm{S} / 2$ & $63 \mathrm{~b}$ & $71 \mathrm{~b}$ & $72 \mathrm{~b}$ & $22 \mathrm{c}$ & $44 \mathrm{~b}$ & $60 \mathrm{c}$ \\
CRI-29 LSI-21 & $\mathrm{S} / 2$ & $79 \mathrm{~b}$ & $82 \mathrm{~b}$ & $86 \mathrm{~b}$ & $18 \mathrm{c}$ & $30 \mathrm{~b}$ & $45 \mathrm{~b}$ \\
LSI-21 & $\mathrm{S} / 4$ & $49 \mathrm{c}$ & $49 \mathrm{c}$ & $56 \mathrm{c}$ & $30 \mathrm{ab}$ & $68 \mathrm{a}$ & $82 \mathrm{ab}$ \\
CRI-29 & $\mathrm{S} / 4$ & $60 \mathrm{c}$ & $67 \mathrm{c}$ & $69 \mathrm{c}$ & $26 \mathrm{~b}$ & $62 \mathrm{a}$ & $74 \mathrm{~b}$ \\
CRI-29+LSI-21 & $\mathrm{S} / 4$ & $76 \mathrm{c}$ & $79 \mathrm{c}$ & $81 \mathrm{c}$ & $24 \mathrm{~b}$ & $36 \mathrm{c}$ & $52 \mathrm{c}$ \\
CONTROL & - & $0 \mathrm{~d}$ & $1 \mathrm{~d}$ & $1 \mathrm{~d}$ & $46 \mathrm{a}$ & $74 \mathrm{a}$ & $92 \mathrm{a}$ \\
LSD & - & 2.43 & 2.17 & 2.92 & 2.38 & 1.64 & 1.08 \\
\hline
\end{tabular}

Data are means of five replicates. Means within a column sharing the same letter are not significantly different from each other at $P=0.05$.

Table 2. Effect of seed treatment with Rhizobium strains on plant growth parameters in soybean.

\begin{tabular}{|c|c|c|c|c|c|c|c|}
\hline Treatments & $\begin{array}{l}\text { Root Length } \\
\text { (cm) }\end{array}$ & $\begin{array}{l}\text { Shoot Length } \\
(\mathrm{cm})\end{array}$ & $\begin{array}{c}\text { Root fresh } \\
\text { wt (g) }\end{array}$ & $\begin{array}{c}\text { Shoot fresh } \\
\text { wt (g) }\end{array}$ & $\begin{array}{c}\text { Root dry } \\
\text { wt (g) }\end{array}$ & $\begin{array}{c}\text { Shoot dry } \\
\text { wt (g) }\end{array}$ & $\begin{array}{c}\text { No. of } \\
\text { nodules }\end{array}$ \\
\hline LSI-21 & $14 d$ & $17 \mathrm{~d}$ & $0.0860 \mathrm{~d}$ & $4.4298 \mathrm{c}$ & $0.0215 \mathrm{~d}$ & $1.1074 \mathrm{c}$ & $10 \mathrm{c}$ \\
\hline CRI-29 & $25 b$ & $33 b$ & $0.3100 \mathrm{c}$ & $5.3560 b$ & $0.0775 \mathrm{c}$ & $1.3390 b$ & $24 b$ \\
\hline LSI-21+CRI-29 & $31 \mathrm{a}$ & $39 a$ & $0.7840 \mathrm{a}$ & $6.2780 \mathrm{a}$ & $0.1450 \mathrm{a}$ & $1.5695 \mathrm{a}$ & $32 \mathrm{a}$ \\
\hline Control (with Nematode) & $7 e$ & $13 \mathrm{e}$ & $0.5800 \mathrm{~b}$ & $2.1178 \mathrm{e}$ & $0.1960 b$ & $0.5295 \mathrm{e}$ & $5 e$ \\
\hline Control (without Nematode) & $19 \mathrm{c}$ & $25 c$ & $0.0240 \mathrm{e}$ & $3.3400 d$ & $0.0060 \mathrm{e}$ & $0.8350 \mathrm{~d}$ & $16 \mathrm{~d}$ \\
\hline LSD & 2.63 & 3.20 & 0.0582 & 0.51 & 0.0146 & 0.1299 & 3.37 \\
\hline
\end{tabular}

Data are means of five replicates. Means within a column sharing the same letters are not significantly different from each other at $P=0.05$. 
Table 3. Effect of seed treatment with Rhizobium strains on nematode reproductive parameters in soybean.

\begin{tabular}{lcccc}
\hline Treatments & No. galls & Egg masses & J2/root & J2/100 $\mathbf{~ c m}^{\mathbf{3}}$ soil \\
\hline LSI-21+CRI-29 & $13 \mathrm{~d}$ & $3 \mathrm{~d}$ & $65 \mathrm{~d}$ & $78 \mathrm{~d}$ \\
CRI-29 & $25 \mathrm{c}$ & $10 \mathrm{c}$ & $126 \mathrm{c}$ & $151 \mathrm{c}$ \\
LSI-21 & $33 \mathrm{~b}$ & $17 \mathrm{~b}$ & $165 \mathrm{~b}$ & 200 \\
Control (with Nematode) & $350 \mathrm{a}$ & $267 \mathrm{a}$ & $2043 \mathrm{a}$ & 893 \\
Control (without Nematode) & $0 \mathrm{e}$ & $0 \mathrm{e}$ & $0 \mathrm{e}$ & $0 \mathrm{e}$ \\
LSD & 3.36 & 2.46 & 1.71 & 1.83 \\
\hline
\end{tabular}

Data are mean of five replicates. Means with in a column sharing the same letter are not significantly different from each other at $P=0.05$.

Table 4. Effect of soil treatment with Rhizobium strains on plant growth parameters in Soybean.

\begin{tabular}{lccccccc}
\hline Treatments & $\begin{array}{c}\text { Root Length } \\
(\mathbf{c m})\end{array}$ & $\begin{array}{c}\text { Shoot } \\
\text { Length }(\mathbf{c m})\end{array}$ & $\begin{array}{c}\text { Root fresh } \\
\mathbf{w t}(\mathbf{g})\end{array}$ & $\begin{array}{c}\text { Shoot fresh } \\
\mathbf{w t}(\mathbf{g})\end{array}$ & $\begin{array}{c}\text { Root dry } \\
\mathbf{w t}(\mathbf{g})\end{array}$ & $\begin{array}{c}\text { Shoot dry } \\
\text { wt }(\mathbf{g})\end{array}$ & $\begin{array}{c}\text { No. of } \\
\text { nodules }\end{array}$ \\
\hline LSI-21 & $25 \mathrm{a}$ & $33 \mathrm{a}$ & $0.6180 \mathrm{a}$ & $5.30 \mathrm{a}$ & $0.1545 \mathrm{a}$ & $1.3250 \mathrm{a}$ & $18 \mathrm{a}$ \\
CRI-29 & $19 \mathrm{~b}$ & $28 \mathrm{~b}$ & $0.240 \mathrm{c}$ & $4.80 \mathrm{~b}$ & $0.0600 \mathrm{c}$ & $1.2000 \mathrm{~b}$ & $10 \mathrm{c}$ \\
LSI-21+CRI-29 & $15 \mathrm{~d}$ & $18 \mathrm{~d}$ & $0.018 \mathrm{e}$ & $2.80 \mathrm{~d}$ & $0.00455 \mathrm{e}$ & $0.9500 \mathrm{~d}$ & $6 \mathrm{~d}$ \\
Control (with Nematode) & $9 \mathrm{c}$ & $12 \mathrm{e}$ & $0.380 \mathrm{~b}$ & $2.20 \mathrm{c}$ & $0.0950 \mathrm{~b}$ & $0.7000 \mathrm{e}$ & $3 \mathrm{e}$ \\
Control (without Nematode) & $4 \mathrm{e}$ & $22 \mathrm{c}$ & $0.100 \mathrm{~d}$ & $4.30 \mathrm{e}$ & $0.0250 \mathrm{~d}$ & $1.0750 \mathrm{c}$ & $13 \mathrm{~b}$ \\
LSD & 2.18 & 2.23 & 0.076 & 0.20 & 0.0190 & 0.0521 & 2.08 \\
\hline
\end{tabular}

Data are means of five replicates. Means within a column sharing the same letters are not significantly different from each other at $P=0.05$.

Table 5. Effect of soil treatment with Rhizobium strains on nematode reproductive parameters in soybean.

\begin{tabular}{lcccc}
\hline Treatments & No. of galls & Egg masses & J2/root & J2/100 cm $\mathbf{~ s o i l ~}^{\mathbf{2}}$ \\
\hline LSI-21+CRI-29 & $28 \mathrm{~d}$ & $12 \mathrm{~d}$ & $141 \mathrm{~d}$ & $170 \mathrm{~d}$ \\
CRI29 & $33 \mathrm{c}$ & $15 \mathrm{c}$ & $167 \mathrm{c}$ & $200 \mathrm{c}$ \\
LSI21 & $41 \mathrm{~b}$ & $20 \mathrm{~b}$ & $207 \mathrm{~b}$ & $249 \mathrm{~b}$ \\
Control (with Nematode) & $390 \mathrm{a}$ & $286 \mathrm{a}$ & $2293 \mathrm{a}$ & $950 \mathrm{a}$ \\
Control (without Nematode) & $0 \mathrm{e}$ & $0 \mathrm{e}$ & $0 \mathrm{e}$ & $0 \mathrm{e}$ \\
LSD & 1.78 & 1.86 & 1.58 & 1.64 \\
\hline
\end{tabular}

Data are means of five replicates. Means within a column sharing the same letters are not significantly different from each other at $P=0.05$.

exposure time with all treatments. Cell free culture filtrates of Rhizobium strains were tested in vitro for their nematicidal efficacy on $M$. incognita eggs. Data indicated that various Rhizobium strains and their different concentrations were highly deleterious to the nematode egg. Standard concentration of CRI-29 alone showed maximum reduction of hatching after an exposure of 72 hours (Table 1). Observably, in vitro findings showed that combined application of standard concentration of both combined application of both strains provide the promising means to manage $M$. incognita infection under greenhouse experiments. So, we used standard concentrations of all Rhizobial strains for confirmation of our in vitro results. Effect of seed priming of soybean with different Rhizobial strains were observed and data on plant growth and nematode reproduction parameters were recorded. Whereby nematode reproductive parameters; no. of galls, egg masses, $\mathbf{J}_{2}$ per root and $100 \mathrm{~cm}^{3}$ of soil were also estimated. Maximum reduction in reproduction parameters was observed in combined application of both strains (CRI-29+LSI-21) followed by individual treatments of CRI-29 and LSI-21. Highest number of egg masses was observed in control treatment having only nematodes (267). Root length of soybean plants was increased significantly with CRI-29+LSI-21 treatment followed by CRI29 (Table 4). Smallest number of egg masses of $M$. incognita was recorded in soil inoculation by simultaneous application of both strains (Table 5).

\section{DISCUSSION}

Annual crop losses due to plant parasitic nematodes were approximately $\$ 10$ billion in the USA States and $\$ 125$ billion globally (Sasser and Freckman, 1987). Although a variety of chemical and other management tools are available to growers, none is perfect with respect to expense, environmental safety or efficacy against the changing nematode biotypes that often occur in agricultural soils. Our results indicated that suppression of nematodes was induced 
by various Rhizobial strains. Both of CRI-29 and LSI-21 at standard concentration demonstrated the significant results over all other treatments after incubation period of 24, 48 and 72 hours at simultaneous treatment respectively. Rhizobia are gram negative and may have lectin binding structures in the lipopolysaccharide layer of cell wall membrane. Therefore, the mechanism responsible for reduction in nematode penetration may be related to the ability of the bacteria to envelop or bind to root surface lectins, thereby interfering with the normal host recognition (Oostendorp and Sikora, 1990). Our results showed that Rhizobial strains have a significant effect on egg hatching and juvenile's mortality. Aqueous extract of microbial antagonists exhibited nematicidal activity which reduced egg hatching of $M$. javanica and increased mortality of larvae with the increase in exposure time. Presumably the production of antibiotics (Dennis and Webster, 1971) and extracellular enzymes (Elad et al., 1982) are involved in antagonisms. Reduction in reproduction parameters of root-knot nematode was observed in our study. Reitz et al. (2000) showed that lipopolysaccharides, LPS (lipid.A) which is defined as an integral part of the outer membrane of the cell, which can extracted from bacterial cultures has an antagonistic agent against nematodes. So, this can explain the results obtained in studying the Rhizobium effect on M. incognita. From these previous results we can conclude that Rhizobium has antagonistic effect against $M$. incognita juveniles which are in harmony with those of Siddiqui et al. (2007). Results obtained from our experimental trials revealed that simultaneous inoculation of Rhizobium strains i.e. CRI-29 and LSI-21 to the soybean plants decreased nematode galls, egg masses and disease severity as well as increased all the growth parameters. In our findings, Rhizobium used as seed dressing significantly improved plant growth and reduced disease intensity of plants due to initial colonizers of rhizospheres of test plants. It is interesting to note that Rhizobia not only showed significant control of root pathogens on leguminous plants like chickpea, mungbean as well as non leguminous plants like okra and sunflower but also increased plant height and fresh shoot weight (Zaki, 2000). The results of in vitro and in vivo experiments indicated that, all tested bacteria have a greatly significant effectiveness for suppressing $M$. incognita. All this suggests that application of rhizobia, which increase nitrogen content and plant growth, can also reduce nematode multiplication (Siddiqui and Mahmood, 1995). The outcome of current research work indicates the potentialities of seed treatment with bacterial antagonists viz., CRI29+LSI-21, CRI-29 and LSI-21 in the suppression of root knot nematode on soybean. Therefore, it is needed to characterize nematicidal compound produced by biological antagonists resulting in control of root knot nematode instead of use of pesticides, which are costly and hazardous.
Conclusion: From the present investigation, it could be concluded that Rhizobium being a good rhizosphere organism not only reduced $M$. incognita population but also increased plant growth. It would seem that rhizobia in soil for field and vegetable crops presumably prevent the contact of pathogenic organisms on roots.

\section{REFERENCES}

Antoun, H. and D. Prevost. 2005. Ecology of plant growth promoting rhizobacteria, pp.1-38. In: Z.A. Siddiqui (ed.), PGPR: Biocontrol and Biofertilization. Springer, Netherlands.

Bridge, J., S.L.J. Page and S. Jordan. 1981. An improved method for staining nematodes in roots. Rothamsted Experimental Report Part 1, p.171.

Dakora, F.D. 2003. Defining new roles for plant and rhizobial molecules in sole and mixed plant cultures involving symbiotic legumes. New Phytol. 158:39-49.

Dennis, C. and R. Webster.1971. Antagonistic properties of species group of Trichoderma. II- Production of volatile antibiotics. Trans. Brit. Mycol. Soc. 57:41-48.

Elad, Y., I. Chet and Y. Hennis. 1982. Degradation of plant pathogenic fungi by Trichoderma

harzianum. Can. J. Microbiol. 28:719-725.

Loper, J.E. and J.S. Buyer.1991. Siderophores in microbial interactions on plant surfaces. Mol. Pl. Microbe Interact. 4:5-13.

Nautiyal, C.S., S. Bhadauria, P. Kumar, H. Lal, R. Mondal and D. Verma. 2000. Stress induced phosphate solubilization in bacteria isolated from alkaline soils. FEMS Microbiol. Lett. 182:291-296.

Oostendorp, M. and R.A. Sikora. 1990. In-vitro interrelationships between rhizosphere bacteria and Heterodera schachtii. Rev. Nematol. 13:269-274.

Reitz, M., K. Rudolph, I. Schroder, S. Hoffmann-Hergarten, J. Hallmann and R.A. Sikora. 2000 Lipopolysaccharides of Rhizobium etli strain G12 act in potato roots as an inducing agent of systemic resistance to infection by the cyst nematode Globodera pallida. Appl. Environ. Microbiol. 66:3515-3518.

Sasser, J.N. and D.W. Freckman. 1987. A world perspective on nematology: the role of the society. p. 7-14. In: J.A. Veech and D.W. Dickson (eds.), Vistas on nematology. Society of Nematologists, Hyattsville, Maryland.

Siddiqui, Z.A. and I. Mahmood. 1995. Some observations on the management of the wilt disease complex on pigeon pea by treatment with vascular arbuscular fungus and biocontrol agent for nematodes. Bioremediation Technol. 54:227-230.

Siddiqui, Z.A., G. Baghel and M.S. Akhtar. 2007. Biocontrol of Meloidogyne javanica by Rhizobium and plant growth-promoting rhizobacteria on lentil. World J. Microbiol. Biotechnol. 23:435-441. 
Somasegaran, P. and H.J. Hoben. 1994. Handbook for Rhizobia: Methods in legume Rhizobium Technology, pp.1-450. Springer-Verlag, New York.

Southey, J.F. 1986. Laboratory methods for work with plant and soil nematodes, p.202, $6^{\text {th }}$ Ed. London, HMSO.
Wrather, J.A. and S.R. Koenning. 2006. Estimates of disease effects on soybean yields in the United States 2003 to 2005. J. Nematol. 38:173-180.

Zaki, M.J. 2000. Biomanagement of root-knot nematodes problem of vegetables, p.131. DFID, UK Research Project Report. Department of Botany, University of Karachi, Karachi- 75270, Pakistan. 